This item was submitted to Loughborough's Research Repository by the author.

Items in Figshare are protected by copyright, with all rights reserved, unless otherwise indicated.

\title{
Mechanism of carbon dioxide and water incorporation in Ba2TiO4: A joint computational and experimental study
}

PLEASE CITE THE PUBLISHED VERSION

https://doi.org/10.1021/acs.jpcc.7b10330

\section{PUBLISHER}

(c) American Chemical Society (ACS)

\section{VERSION}

AM (Accepted Manuscript)

\section{PUBLISHER STATEMENT}

This work is made available according to the conditions of the Creative Commons Attribution-NonCommercialNoDerivatives 4.0 International (CC BY-NC-ND 4.0) licence. Full details of this licence are available at: https://creativecommons.org/licenses/by-nc-nd/4.0/

\section{LICENCE}

CC BY-NC-ND 4.0

\section{REPOSITORY RECORD}

McSloy, Adam J., Ivan Trussov, Abbey Jarvis, David J. Cooke, Peter R. Slater, and Pooja M. Panchmatia. 2019. "Mechanism of Carbon Dioxide and Water Incorporation in Ba2tio4: A Joint Computational and Experimental Study". figshare. https://hdl.handle.net/2134/32260. 


\title{
PHE JOURNAL OF CHEMICAL CHEMTR University
}

Subscriber access provided by LOUGHBOROUGH UNIVERSITY LIBRARY

Article

\author{
Mechanism of Carbon Dioxide and Water \\ Incorporation in BaTiO: A Materials Degradation Study
}

Adam J. McSloy, Ivan Trussov, Abbey Jarvis, David J Cooke, Peter R. Slater, and Pooja M. Panchmatia

J. Phys. Chem. C, Just Accepted Manuscript • DOI: 10.1021/acs.jpcc.7b10330 • Publication Date (Web): 22 Dec 2017

Downloaded from http://pubs.acs.org on January 3, 2018

\section{Just Accepted}

"Just Accepted" manuscripts have been peer-reviewed and accepted for publication. They are posted online prior to technical editing, formatting for publication and author proofing. The American Chemical Society provides "Just Accepted" as a free service to the research community to expedite the dissemination of scientific material as soon as possible after acceptance. "Just Accepted" manuscripts appear in full in PDF format accompanied by an HTML abstract. "Just Accepted" manuscripts have been fully peer reviewed, but should not be considered the official version of record. They are accessible to all readers and citable by the Digital Object Identifier (DOI $\left.{ }^{8}\right)$. "Just Accepted" is an optional service offered to authors. Therefore, the "Just Accepted" Web site may not include all articles that will be published in the journal. After a manuscript is technically edited and formatted, it will be removed from the "Just Accepted" Web site and published as an ASAP article. Note that technical editing may introduce minor changes to the manuscript text and/or graphics which could affect content, and all legal disclaimers and ethical guidelines that apply to the journal pertain. ACS cannot be held responsible for errors or consequences arising from the use of information contained in these "Just Accepted" manuscripts. 


\section{Introduction}

The $\mathrm{A}_{2} \mathrm{BO}_{4}$ material class is a diverse group of oxometallates with over 50 know crystal structures, many of which contain isolated or linked tetrahedral frameworks. ${ }^{1,2}$ They are of huge technological importance and one such material is barium orthotitanate, relatively close to its electroceramic cousin $\mathrm{BaTiO}_{3}$. Numerous compounds exist within the $\mathrm{BaO}-\mathrm{TiO}_{2}$ system, several being good electroceramics. ${ }^{3,4}$ Of these compounds, only barium orthotitanate $\left(\mathrm{Ba}_{2} \mathrm{TiO}_{4}\right)$ is both barium-rich and stable. ${ }^{5,6}$ This material has a high melting point of $1860{ }^{\circ} \mathrm{C}$ and is unusual as it has $\mathrm{Ti}^{4+}$ ions tetrahedrally coordinated to oxygen. ${ }^{7,8}$ It has recently gained a renewed interest due to its $\mathrm{CO}_{2}$ sorption properties, which emanates from a reversible $\mathrm{Ba}_{2} \mathrm{TiO}_{4}+\mathrm{CO}_{2} \rightarrow$

\footnotetext{
a Department of Chemistry, Loughborough University, Loughborough LE11 3TU, United Kingdom.

${ }^{b}$ School of Chemistry, The University of Birmingham, Edgbaston, Birmingham B15 2TT, United Kingdom.

${ }^{c}$ Department of Chemistry, University of Huddersfield, Huddersfield HD1 3DH, United Kingdom.

$\dagger$ Electronic Supplementary Information (ESI) available: [details of any supplementary information available should be included here]. See DOI:
}

$\mathrm{BaCO}_{3}+\mathrm{BaTiO}_{3}$ process, which makes it a promising candidate for carbon capture applications. ${ }^{9-13}$ Like many other barium titanates, it is predicted to be a wide-gap insulator. ${ }^{14}$

$\mathrm{Ba}_{2} \mathrm{TiO}_{4}$ is highly hygroscopic and has been reported to exists in a low temperature monoclinic $P 2_{1} / n \beta$-phase and a high temperature orthorhombic $P 2{ }_{1} n b \alpha^{\prime}$-phase, the latter being a tripled $b$-axis superstructure of the former. ${ }^{15,16}$ These studies have shown that the $\mathrm{Ba}_{2} \mathrm{TiO}_{4}$ structure can be described as a series of isolated $\mathrm{TiO}_{4}$ tetrahedra separated by Ba ions which occupy 7 (or 6 in the $\alpha^{\prime}$ phase) and 8 coordinate sites, shown in Figure 1. Further studies have suggested that the phase transformation temperature can be affected by grain size and impurity effects, with some reports showing that lower temperature synthesis routes can stabilise the high temperature orthorhombic $\alpha^{\prime}$-phase. ${ }^{17-20}$ However, our prior work on Ba containing perovskite systems have shown that at such lower temperatures carbonate can be present in the structure. ${ }^{21}$ In this paper, we therefore present a detailed modelling and experimental investigations, elucidating the mechanisms of $\mathrm{CO}_{2}$ and $\mathrm{H}_{2} \mathrm{O}$ incorporation, and propose that it is $\mathrm{CO}_{2}$ incorporation as carbonate, which is responsible for the stabilisation this phase. 


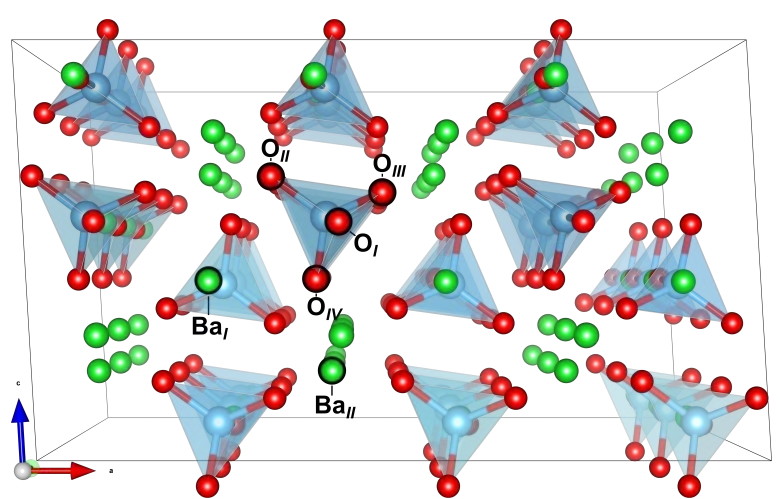

(a)

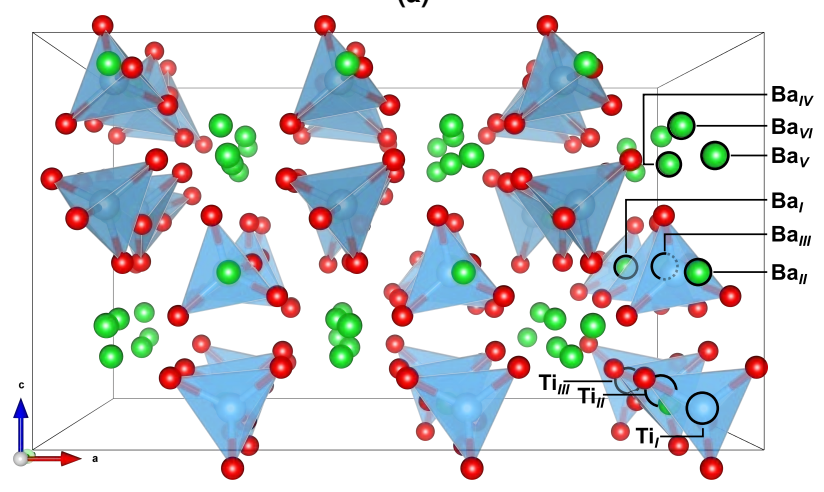

(b)

Fig. 1 Structure of a) $\beta-\mathrm{Ba}_{2} \mathrm{TiO}_{4}\left(3 \times 3 \times 1\right.$ supercell) and b) $\alpha^{\prime}-\mathrm{Ba}_{2} \mathrm{TiO}_{4}$ $(3 \times 1 \times 1$ supercell) with $\mathrm{Ba}, \mathrm{Ti}$ and $\mathrm{O}$ ions represented as green, blue and red spheres respectively and $\mathrm{TiO}_{4}$ tetrahedra in blue.

\section{Methodology}

\subsection{Computational}

The computational methods employed herein are reviewed in brief below, however more comprehensive descriptions can be found elsewhere. ${ }^{22-24}$ Interatomic potential based energy minimisation calculations were performed using the general utility lattice program (GULP), ${ }^{25,26}$ and structural images rendered using VESTA. ${ }^{27}$

Calculations were based on the Born model for ionic solids where long and short-range pairwise terms are used to describe the Coulombic, and the Pauli's repulsive and van der Waals interactions respectively. In this study, short-range ionic interactions were modelled using the Buckingham potential: ${ }^{28}$

$$
\Phi_{i j}(r)=A_{i j} \exp \left(-\frac{r}{\rho_{i j}}\right)-\frac{C_{i j}}{r^{6}}
$$

Where $\Phi_{i j}$ is the potential energy resulting from the interaction of ions $i$ and $j$ at distance $r$, and $A_{i j}, \rho_{i j}$ and $C_{i j}$ are the empirically derived potential parameters specific to the $i-j$ ion pair. Ionic polarisability, which is particularly important when considering charged defects, was described using the Dick and Overhauser shell model. ${ }^{29}$ Interatomic potentials, and shell parameters, from literature were screened to identify a preliminary model. ${ }^{30-32}$ Each potential was then fitted to the experimental $\beta$ $\mathrm{Ba}_{2} \mathrm{TiO}_{4}$ structure, and vetted to its respective binary oxide struc- ture and elastic constants, to yield those in table $1 .^{15}$

Intramolecular $\mathrm{O}-\mathrm{H}$ and $\mathrm{C}-\mathrm{O}$ interactions within the $\mathrm{OH}^{-}$and $\mathrm{CO}_{3}^{2-}$ units were modelled with the Coulomb-subtracted Morse potential, equation 2 , as it better describes their covalent character. $^{33}$

$$
\Phi_{i j}(r)=D_{e}\left[\left(1-\exp \left(-a\left(r-r_{0}\right)\right)\right)^{2}-1\right]
$$

Where $D_{e}$ and $a$ are depth and width of the potential well respectively and $r_{0}$ is the equilibrium bond distance. The parameters selected to model $\mathrm{OH}^{-}$units in $\mathrm{Ba}_{2} \mathrm{TiO}_{4}$ are given in table ?? ${ }^{34}$ In accordance with Panchmatia et al. ${ }^{34}$, partial charges of -1.4263 and 0.4263 were placed on $\mathrm{O}$ and $\mathrm{H}$ respectively to model the $\mathrm{OH}^{-}$unit's dipole moment. The $\mathrm{CO}_{3}^{2-}$ was treated with an $\mathrm{O}$ shell $(-1.380)$ and a partial charge on the carbon (1.450). A three-body potential was also included to maintain the $\mathrm{CO}_{3}^{2-}$ group's $120^{\circ}$ bond angle. This, shown in equation 3 , is parameterised by its equilibrium bond angle, $\theta_{0}$, and a constant, $k_{2}$.

$$
\Phi_{i j k}\left(\theta_{i j k}\right)=\frac{1}{2} k_{2}\left(\theta_{i j k}-\theta_{0}\right)^{2}
$$

Finally, the torsional term shown in equation 4 is necessary to model the potential energy associated with the out-of-plane bending of the $\mathrm{CO}_{3}^{2-}$ group. In the torsional potential, $k_{4}, \theta_{0}$ and $n$ represent a constant, equilibrium torsion angle and number of stable minima respectively.

$$
\Phi_{i j j l}\left(\theta_{i j j l}\right)=k_{4}\left(1-\cos \left(n \theta_{i j k l}-\theta_{0}\right)\right)
$$

The $\mathrm{CO}_{3}^{2-}$ potential model used, table ??, is based on that by Archer et al. ${ }^{35}$, where all intramolecular interactions act on the oxygen's core, and includes Kerisit and Parker's ${ }^{36} \mathrm{C}^{\mathrm{C}} \mathrm{O}_{\text {Lattice }}$ Buckingham potential. The torsional $k$ term was refined (1.10 $\mathrm{eV}$ ) using ab initio quantum mechanical coupled cluster CCSD(T) methods in order to improve the model's stability.

Point defects were modelled using the Mott Littleton method. ${ }^{37}$ This method partitions the area encompassing the defect into two spherical regions. Ions in the inner region are treated explicitly, while those in the outer region are handled more approximately by quasi-continuum methods. ${ }^{37}$ Convergence tests for both regions showed no significant change to defect energy beyond a short-range Mott Littleton cut-off of $12.00 \AA$ (inner region) and $24.00 \AA$ (outer region) for single defect calculations and of 14.00 $\AA$ and $28.00 \AA$ A respectively for the molecular defect calculations. The $\mathrm{CO}_{3}^{2-}$ defects were modelled using the supercell method. ${ }^{37}$

Defect reaction mechanisms are described herein using KrögerVink notation. ${ }^{38}$ In this, a species is represented as $\mathrm{A}_{x}^{q}$, where A corresponds to the ion itself or $\mathrm{V}$ if a vacancy. The subscript $x$ represents the species' lattice site, and an $i$ is used for interstitials. The superscript $q$ is the species' effective electronic charge relative to the lattice site it occupies, with positive and negative charges represented by dots and primes respectively and no charge by a cross.

The deliberate choice of using a classical interatomic based approach was for many reasons listed below:

1) Given the number of calculations required and the size of each system, a DFT based approach would have been rather costly from a computational stand point. 
Table 1 Interatomic potential and shell model parameters for $\mathrm{Ba}_{2} \mathrm{TiO}_{4}$

used in this work

a) Buckingham potential parameters ${ }^{\ddagger}$.

\begin{tabular}{llll}
\hline Interaction & $A(\mathrm{eV})$ & $\rho(\AA)$ & $C\left(\mathrm{eV} \AA^{6}\right)$ \\
\hline $\mathrm{Ba}^{2+}-\mathrm{O}^{2-}$ & 4939.2 & 0.3074 & 0.00 \\
$\mathrm{Ti}^{4+}-\mathrm{O}^{2-}$ & 1946.9 & 0.3020 & 9.22 \\
$\mathrm{O}^{2-}-\mathrm{O}^{2-}$ & 22764.3 & 0.1490 & 28.33 \\
\hline
\end{tabular}

b) Shell model parameters

\begin{tabular}{lll}
\hline Ion & Shell Charge $(\mathrm{e})$ & $k\left(\mathrm{eV} \AA^{-2}\right)$ \\
\hline $\mathrm{O}^{2-}$ & -2.91 & 49.53 \\
\hline ₹ A short range potential cut-off of $12.00 \AA$ was enforced in all static-lattice calculations.
\end{tabular}

2) All other aspects of the $\mathrm{Ba}_{2} \mathrm{TiO}_{4}$ material investigation (for example defect formation, doping, defect clustering, proton defect formations) would also need to be conducted using DFT based methods to be consistent. This is particularly important when considering interactions between dopant incorporation and carbonate formation as classically calculated energy values would be added to DFT calculated ones introducing internal consistency issues.

3) A rigorously tested and verified classical interatomic based " $\mathrm{Ba}_{2} \mathrm{TiO}_{4}-\mathrm{CO}_{3}$ " model, is the springboard for future molecular dynamics simulations, where investigations of the diffusion of absorbed carbonate and protonic defects in $\mathrm{Ba}_{2} \mathrm{TiO}_{4}$ can be performed in larger simulation cells and for nanosecond simulation times. Besides, such methods have been successfully employed to provide atomistic level insights into carbonate and protonic defects in olivine, apatite-type and many other materials. ${ }^{39-43}$

\subsection{Experimental}

In order to compare with the modelling studies a $5 \mathrm{~g}$ sample of monoclinic $\mathrm{Ba}_{2} \mathrm{TiO}_{4}$ was prepared by concomitantly mixing $\mathrm{BaCO}_{3}$ and $\mathrm{TiO}_{2}$ in the $2: 1$ molar ratio, and heating at $950{ }^{\circ} \mathrm{C}$ for 12 hours, before regrinding and reheating at $1100{ }^{\circ} \mathrm{C}$ for 12 hours and furnace cooling. The sample was analysed by X-ray powder diffraction (Bruker D8 diffractometer, $\mathrm{Cu} \mathrm{K}_{\mathrm{alpha}}$ radiation), which confirmed the formation of the monoclinic $\beta-\mathrm{Ba}_{2} \mathrm{TiO}_{4}$ phase. Approximately $0.5 \mathrm{~g}$ portions of this phase were heated under different conditions to investigate any transformation to the $\alpha^{\prime}-\mathrm{Ba}_{2} \mathrm{TiO}_{4}$ phase. Subsequent analysis was performed using TG-MS (Netzsch STA 449 F1 Jupiter Thermal Analyser) to determine any mass losses. Samples were heated under $\mathrm{N}_{2}$ with a heating rate of $10^{\circ} \mathrm{C} \mathrm{min}^{-1}$ up to $1100^{\circ} \mathrm{C}$.

\section{Results and Discussion}

\subsection{Structural Modelling and Intrinsic Defects}

At room temperature, $\mathrm{Ba}_{2} \mathrm{TiO}_{4}$ crystallises in the monoclinic $P 2_{1} / n \beta$-phase shown in figure 1a (alternative view provided in figure ??). This structure has 4 distinct $\mathrm{O}^{2-}$ sites, $2 \mathrm{Ba}^{2+}$ sites and $1 \mathrm{Ti}^{4+}$ site. The $\mathrm{Ba}_{I}$ and $\mathrm{Ba}_{I I}$ sites are coordinated to 7 and $8 \mathrm{O}^{2-}$ ions respectively, while each $\mathrm{Ti}$ ion is coordinated tetrahedrally to $4 \mathrm{O}^{2-}$ ions. ${ }^{15,44}$ These isolated tetrahedra alternate with $\mathrm{Ba}_{I}$ ions to form $\mathrm{TiO}_{4}-\mathrm{Ba}_{I}$ channels down the $b$-axis. The high tem-
Table 2 Comparison of calculated and experimental lattice parameters of the (a) $\beta$ and (b) $\alpha^{\prime}$ phases of $\mathrm{Ba}_{2} \mathrm{TiO}_{4}$.

\begin{tabular}{llll}
\hline \multicolumn{4}{c}{ (a) Lattice parameters of $\beta-\mathrm{Ba}_{2} \mathrm{TiO}_{4}$} \\
\hline Parameter & Experimental & & \\
\hline Calculated & Difference (\%) \\
\hline a $(\AA)$ & $6.096(4)$ & 6.100 & $0.004(0.06)$ \\
b $(\AA)$ & $7.681(6)$ & 7.676 & $-0.005(-0.07)$ \\
c $(\AA)$ & $10.545(9)$ & 10.488 & $-0.057(-0.54)$ \\
$\alpha=\gamma\left({ }^{\circ}\right)$ & 90.000 & 90.000 & $0.000(0.00)$ \\
$\beta\left({ }^{\circ}\right)$ & $92.990(6)$ & 93.425 & $0.435(0.47)$ \\
\hline
\end{tabular}

(b) Lattice parameters of $\alpha^{\prime}-\mathrm{Ba}_{2} \mathrm{TiO}_{4}$

\begin{tabular}{lllc}
\hline Parameter & Experimental $^{16}$ & Calculated & Difference (\%) \\
\hline a $(\AA)$ & $6.107(8)$ & 6.118 & $0.011(0.18)$ \\
b $(\AA)$ & $22.952(4)$ & 22.969 & $0.017(0.08)$ \\
c $(\AA)$ & $10.540(2)$ & 10.476 & $-0.064(-0.61)$ \\
$\alpha=\beta=\gamma\left({ }^{\circ}\right)$ & 90.000 & 90.000 & $0.000(0.00)$ \\
\hline
\end{tabular}

Experimental standard deviations of the last digit given in the parenthesise of the first column.

perature orthorhombic $P 2{ }_{1} n b \alpha^{\prime}$-phase, shown in figure $1 \mathrm{~b}$, is a tripled $b$-axis superstructure of the $\beta$-phase, and therefore shares the same basic structure. The $\alpha^{\prime}$-phase contains 6 symmetrically inequivalent $\mathrm{Ba}$ sites, however, sites $\mathrm{Ba}_{I}-\mathrm{Ba}_{I I I}$ are similar to an under-coordinated $\beta-\mathrm{Ba}_{I}$ site and sites $\mathrm{Ba}_{I V}-\mathrm{Ba}_{V I}$ are comparable to $\beta-\mathrm{Ba}_{I I}$. Likewise, the 3 unique tetrahedra in the $\alpha^{\prime}$-phase are similar to those of the $\beta$-phase but with slightly different orientations.

Using the inter-ionic potentials listed in Table1, the calculated lattice parameters of both $\beta$ and $\alpha^{\prime}$-phase $\mathrm{Ba}_{2} \mathrm{TiO}_{4}$ shows good fit to within $1 \%$ of the experimental crystal structure, table $2 .{ }^{15,16}$ The cation-anion distances, given for the $\beta$-phase in table ??, are also found to be in reasonable agreement, despite the ambiguous experimental crystal structure. The search for transferable inter-ionic potential models is not trivial particularly when the differences between the phases are so subtle.

The calculated point defect energies, presented in table ??, suggest the formation of intrinsic defects in both phases of $\mathrm{Ba}_{2} \mathrm{TiO}_{4}$ to be energetically unfavourable. Therefore, the concentration of such defects, even at high temperatures, will be negligible and undoped $\mathrm{Ba}_{2} \mathrm{TiO}_{4}$ is likely to be a poor oxide ion conductor. This is not unexpected given that similar findings have been reported for the isostructural material $\beta-\mathrm{Ca}_{2} \mathrm{SiO}_{4} \cdot{ }^{44}$

\subsection{Water Incorporation}

$\mathrm{Ba}_{2} \mathrm{TiO}_{4}$ is a hygroscopic material and particularly at elevated temperatures, tends to decompose on contact with humid air. 45,46 However, it may be feasible for small concentrations of water to be incorporated into $\mathrm{Ba}_{2} \mathrm{TiO}_{4}$ as protonic defects with minimal decomposition. In some materials, the defects formed upon water incorporation lead to enhanced proton and oxide ion conductivities. ${ }^{34,47}$ For these reasons, the favouribility of protonic defects have been investigated.

In the first stage, the proton defect location and energy were determined. Our simulations suggest protonic defects will bind to oxide ions and therefore have been treated as hydroxide units 


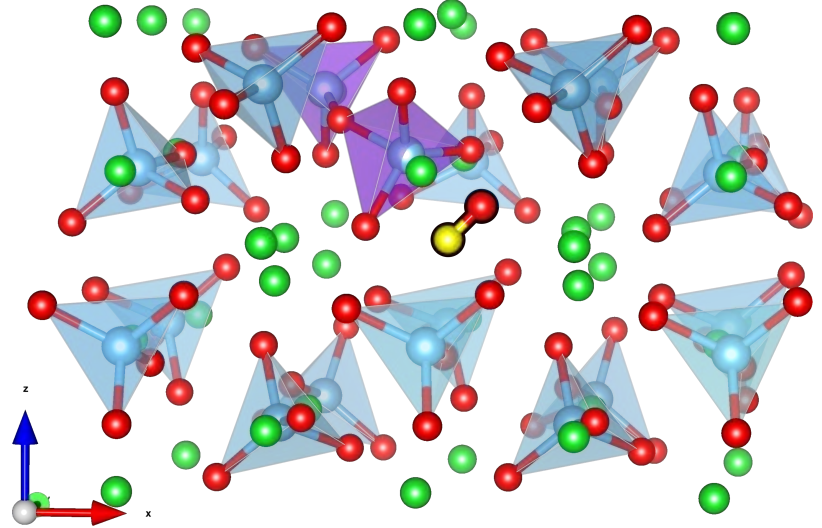

(a)

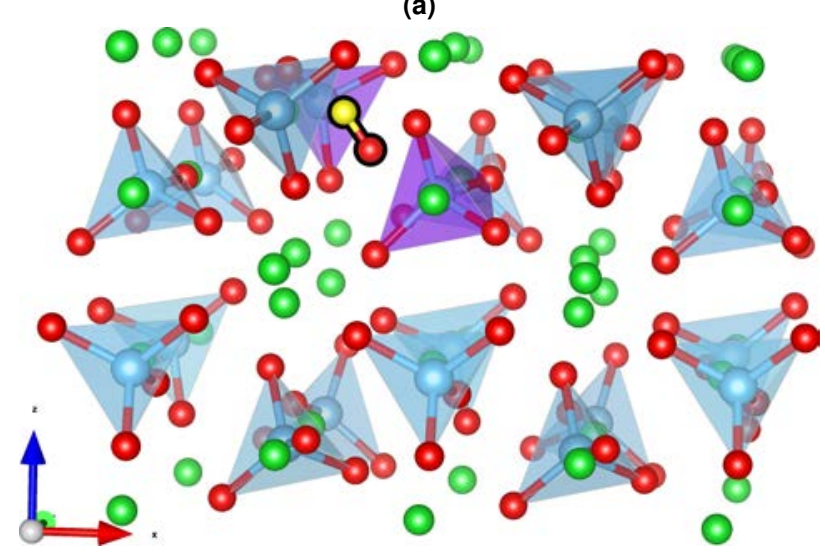

(b)

Fig. 2 a) $\mathrm{HO}_{\mathrm{O}}^{\circ}$ and b) $\mathrm{OH}_{i}^{\prime}$ defect in $\alpha^{\prime}-\mathrm{Ba}_{2} \mathrm{TiO}_{4}$ with $\mathrm{Ba}, \mathrm{Ti}, \mathrm{O}$ and $\mathrm{H}$ ions shown as green, blue, red and yellow spheres respectively and $\mathrm{TiO}_{4}$ tetrahedra in blue, purple polyhedra represent " $\mathrm{Ti}_{2} \mathrm{O}_{7}$ " units in sub-figure $a$ and distorted- $-\mathrm{TiO}_{4}$ units in sub-figure $\mathrm{b}$.

$\left(\mathrm{OH}^{-}\right)$. Equations 5 to 8 represent the viable mechanisms by which water can be incorporated either on lattice oxide sites $\left(\mathrm{OH}_{\mathrm{O}}^{\circ}\right)$ or interstitial sites $\left(\mathrm{OH}_{i}^{\prime}\right) .{ }^{48}$ A series of Mott-Littleton calculations were carried out to determine the energies, structures and locations of these defects.

In the lowest energy $\alpha^{\prime}$-phase structure, figure $2 \mathrm{a}$, the hydroxide's oxygen remains at the original $\mathrm{O}_{I I I}$ lattice site, and a single oxygen bridged " $\mathrm{Ti}_{2} \mathrm{O}_{7}$ " unit is formed reminiscent of the " $\mathrm{Ga}_{2} \mathrm{O}_{7}$ " units seen in the structurally related $\mathrm{La}_{0.8} \mathrm{Ba}_{1.2} \mathrm{GaO}_{3.9} \cdot{ }^{49}$ With a shortest HO-Ti distance of $\sim 2.4 \AA$ the $\mathrm{OH}^{-}$lies primarily on the outside of the $\mathrm{Ti}$ ion's coordination sphere. The $\mathrm{OH}_{i}^{\prime}$ defect structure, figure $2 \mathrm{~b}$, shows that the hydroxide's oxygen lies approximately halfway between a pair of nearest neighbouring Ti ions. Although the hydroxide unit is $\sim 2.5 \AA$ away from the two Ti ions its presence does distort the neighbouring $\mathrm{O}_{I}$ sites, albeit to a lesser extent than that seen for the $\mathrm{OH}_{\mathrm{O}}^{-}$defect.

Following the determination of the most favourable location for the proton defects, the various mechanisms of water incorporation were considered in order to determine the water incorporation energies. The first two mechanisms, represent water incorporated as $\mathrm{OH}_{\mathrm{O}}^{\cdot}$ units and an oxygen or hydroxyl interstitial, shown in equations 5 and 6 . This is achieved through the forma-
Table 3 Water incorporation energies (eV) for mechanisms 5 to 8.

\begin{tabular}{lcc}
\hline Equation & $\beta$-phase & $\alpha^{\prime}$-phase \\
\hline 5: $\mathrm{E}_{\mathrm{H}_{2} \mathrm{O}}=2 \mathrm{OH}_{\mathrm{O}}^{\bullet}+\mathrm{O}_{i}^{\prime \prime}+\mathrm{E}_{\mathrm{PT}}$ & 7.80 & 7.17 \\
6: $\mathrm{E}_{\mathrm{H}_{2} \mathrm{O}}=\mathrm{OH}_{\mathrm{O}}^{\circ}+\mathrm{OH}_{i}^{\prime}+\mathrm{E}_{\mathrm{PT}}$ & 4.32 & 3.96 \\
7: $\mathrm{E}_{\mathrm{H}_{2} \mathrm{O}}=2 \mathrm{OH}_{\mathrm{O}}^{\bullet}-\mathrm{V}_{O}^{\bullet}+\mathrm{E}_{\mathrm{PT}}$ & 0.83 & 0.47 \\
8: $\mathrm{E}_{\mathrm{H}_{2} \mathrm{O}}=2 \mathrm{OH}_{i}^{\prime}-\mathrm{O}_{i}^{\prime \prime}+\mathrm{E}_{\mathrm{PT}}$ & 0.85 & 0.75 \\
\hline
\end{tabular}

tion of combinations of $\mathrm{OH}_{\mathrm{O}}^{-}$defects and $\mathrm{OH}_{i}^{\prime}$ defects. The first mechanism has been proposed to increase oxide ion conductivity in some materials due to the oxygen interstitials it formation. ${ }^{34}$

$$
\begin{aligned}
& \mathrm{H}_{2} \mathrm{O}+2 \mathrm{O}_{\mathrm{O}}^{\mathrm{x}} \rightarrow 2 \mathrm{OH}_{\mathrm{O}}^{\cdot}+\mathrm{O}_{i}^{\prime \prime} \\
& \mathrm{H}_{2} \mathrm{O}+\mathrm{O}_{\mathrm{O}}^{\mathrm{x}} \rightarrow \mathrm{OH}_{\mathrm{O}}^{\cdot}+\mathrm{OH}_{i}^{\prime}
\end{aligned}
$$

The mechanisms considered in equations 7 and 8 are specific to the presence of oxygen vacancies or interstitials in $\mathrm{Ba}_{2} \mathrm{TiO}_{4}$. In equation $7, \mathrm{H}_{2} \mathrm{O}$ reacts with an oxygen vacancy to form a pair of $\mathrm{OH}_{\mathrm{O}}^{\circ}$ units. This mechanism is responsible for proton conduction in some $\mathrm{A}_{2} \mathrm{BO}_{4}$-type materials. ${ }^{47,50,51}$ In equation $8, \mathrm{H}_{2} \mathrm{O}$ reacts with an oxygen interstitial forming a pair of $\mathrm{OH}_{i}^{\prime}$ defects. If favourable, these two mechanisms would eliminate any oxygen defects present, such as those formed through doping, (see supplementary material for further information) and are therefore likely to curb oxide ion conduction.

$$
\begin{aligned}
& \mathrm{H}_{2} \mathrm{O}+V_{\mathrm{O}}^{\ddot{ }}+\mathrm{O}_{\mathrm{O}}^{\times} \rightarrow 2 \mathrm{OH}_{\mathrm{O}}^{\cdot} \\
& \mathrm{H}_{2} \mathrm{O}+\mathrm{O}_{\mathrm{i}}^{\prime \prime} \rightarrow 2 \mathrm{OH}_{i}^{\prime}
\end{aligned}
$$

Water incorporation energies $\left(\mathrm{E}_{\mathrm{H}_{2} \mathrm{O}}\right)$ for these mechanisms are presented in table 3 and were calculated using the equations listed therein. In this study, an $\mathrm{E}_{\mathrm{PT}}$ value of $-9.74 \mathrm{eV}$ was selected, which represents the energy of the gas phase proton transfer reaction $\mathrm{H}_{2} \mathrm{O}+\mathrm{O}^{2-} \rightarrow 2 \mathrm{OH}^{-} .{ }^{52}$ Our calculations suggest that water incorporation via mechanisms 5 and 6 is unfavourable, indicating that significant water inclusions are unlikely in pristine $\mathrm{Ba}_{2} \mathrm{TiO}_{4}$. However, water incorporation via the oxide defect interaction mechanisms 7 and 8 are more favourable with much lower incorporation energies.. This suggests that oxide ion defects formed in $\mathrm{Ba}_{2} \mathrm{TiO}_{4}$ as a result of doping may be supplanted by hydroxide ions and possibly reducing oxide ion conductivities, see supplementary information for some examples of water incorporation on doping. Furthermore, as their incorporation into the $\alpha^{\prime}$-phase is more favourable water based defects, if present, may stabilise the $\alpha^{\prime}$-phase at lower temperatures in a similar fashion to doping. ${ }^{17,18}$

\subsection{Carbon Dioxide Incorporation (Modelling Studies)}

As $\mathrm{Ba}_{2} \mathrm{TiO}_{4}$ is commonly synthesised via the carbonate route, small concentrations of $\mathrm{CO}_{2}$ based impurity defects are likely, particularly at low synthesis temperatures. Furthermore, there is growing evidence of $\mathrm{CO}_{2}$ incorporation as a carbonate ion in many systems prepared by lower temperature routes, e.g. reports of carbonate incorporation in perovskites, Hancock et al. ${ }^{21}$, 
Table 4 Carbon dioxide incorporation energies for mechanisms 9 to 13.

\begin{tabular}{lcc}
\hline \multirow{2}{*}{ Equation } & \multicolumn{2}{c}{ Defect Energy $(\mathrm{eV})$} \\
\cline { 2 - 3 } & $\beta$-phase & $\alpha^{\prime}$-phase \\
\hline 9: $\mathrm{E}_{\mathrm{CO}_{2}}=\left[\left(\mathrm{CO}_{3}\right)_{i}^{\prime \prime}+\mathrm{V}_{\mathrm{O}}^{*}\right]+\mathrm{E}_{\mathrm{OT}}$ & 0.35 & -0.05 \\
10: $\mathrm{E}_{\mathrm{CO}_{2}}=\left(\mathrm{CO}_{3}\right)_{i}^{\prime \prime}+\mathrm{V}_{\mathrm{O}}^{*}+\mathrm{E}_{\mathrm{OT}}$ & 4.99 & 4.23 \\
11: $\mathrm{E}_{\mathrm{CO}_{2}}=\left(\mathrm{CO}_{3}\right)_{i}^{\prime \prime}-\mathrm{O}_{i}^{\prime \prime}+\mathrm{E}_{\mathrm{OT}}$ & -1.97 & -2.47 \\
12: $\mathrm{E}_{\mathrm{CO}_{2}}=\left[\left(\mathrm{CO}_{3}\right)_{i}^{\prime \prime}+2 \mathrm{~V}_{\mathrm{O}}^{*}\right]+\mathrm{E}_{\mathrm{OT}}-\mathrm{V}_{\mathrm{O}}^{*}$ & -3.08 & -3.24 \\
13: $\mathrm{E}_{\mathrm{CO}_{2}}=\frac{1}{2}\left[\left(\mathrm{CO}_{3}\right)_{i}^{\prime \prime}+2 \mathrm{~V}_{\mathrm{O}}^{*}\right]+\mathrm{E}_{\mathrm{OT}}+\frac{1}{2}\left(\mathrm{CO}_{3}\right)_{i}^{\prime \prime}$ & 0.96 & 0.49 \\
\hline
\end{tabular}

and the recent report showing that " $\mathrm{YAlO}_{3}$ " is actually an oxide carbonate, of form $\mathrm{Y}_{3} \mathrm{Al}_{3} \mathrm{O}_{8} \mathrm{CO}_{3} .{ }^{53}$ among others. ${ }^{43,53,54}$ Indeed below $750{ }^{\circ} \mathrm{C} \mathrm{Ba}_{2} \mathrm{TiO}_{4}$ is known to react with $\mathrm{CO}_{2}$ to form $\mathrm{BaCO}_{3}$ and $\mathrm{BaTiO}_{3}$, however, this reaction reverses at higher temperatures. ${ }^{18}$ While $\mathrm{Ba}_{2} \mathrm{TiO}_{4}$ has been studied for its $\mathrm{CO}_{2}$ sorption properties, investigations focused on macroscopic rather than atomistic effects. ${ }^{9,10,18,20,55}$

During $\mathrm{Ba}_{2} \mathrm{TiO}_{4}$ decomposition, it has been proposed that $\mathrm{CO}_{2}$ reacts at the surface, where there will be more defects, to form $\mathrm{CO}_{3}^{2-}$ and finally $\mathrm{BaCO}_{3} .{ }^{20}$ Particularly during synthesis, $\mathrm{CO}_{2}$ may react with an interstitial or lattice oxide ion to produce a carbonate anion. Therefore, $\mathrm{CO}_{2}$ based defects were treated as $\mathrm{CO}_{3}^{2-}$ ions in this investigation to determine whether bulk carbonate defects may form favourably through combination of $\mathrm{CO} 2$ and lattice oxygen.

To correctly calculate the $\mathrm{CO}_{2}$ incorporation energies $\left(\mathrm{E}_{\mathrm{CO}_{2}}\right)$ a term, similar to the proton transfer term $\left(\mathrm{E}_{\mathrm{PT}}\right)$, must be included to represent the energy of the reaction $\mathrm{CO}_{2}+\mathrm{O}^{2-} \rightarrow \mathrm{CO}_{3}^{2-}$. As no value for this term (referred to as $\mathrm{E}_{\mathrm{OT}}$ ) exists in literature a value of $-14.37 \mathrm{eV}$ has been derived in this work following the procedure detailed in the supplementary material. All carbonate defect calculations were conducted in $\beta-4 \times 3 \times 2$ and $\alpha^{\prime}-4 \times 1 \times 2$ supercells.

Five $\mathrm{CO}_{2}$ incorporation mechanisms were considered (equation 9 - 13). In equation $9, \mathrm{CO}_{2}$ reacts with a lattice oxide ion to form a carbonate interstitial with an oxygen vacancy $\left(\left[\left(\mathrm{CO}_{3}\right)_{i}^{\prime \prime}+\mathrm{V}_{\mathrm{O}}^{* *}\right]\right)$ at the nearest neighbour tetrahedra. It should be noted that square brackets denote clustered defects, and so requires an additional binding energy term $(-4.28 \mathrm{eV})$ calculated as the difference between a carbonate group next to an oxygen vacancy and a carbonate group infinitely separated from the oxygen vacancy.

$$
\mathrm{CO}_{2(\mathrm{~g})}+\mathrm{O}_{\mathrm{O}}^{\times} \rightarrow\left[\left(\mathrm{CO}_{3}\right)_{i}^{\prime \prime}+\mathrm{V}_{\mathrm{O}} \cdot\right]
$$

It can be seen from the calculated $\mathrm{E}_{\mathrm{CO}_{2}}$ values in table 4 that this mechanism is favourable, particularly in the $\alpha^{\prime}$-phase, suggesting that such defects are likely in pristine $\mathrm{Ba}_{2} \mathrm{TiO}_{4}$ in accord with the experimental data. All subsequent discussions regarding carbonate defect structures will focus on those in the $\alpha^{\prime}$-phase as they are the most favourable, see table 4. Rather than forming a joint tetrahedra-carbonate defect like those seen in $\mathrm{Y}_{3} \mathrm{Al}_{3} \mathrm{O}_{8} \mathrm{CO}_{3}$, the $\mathrm{CO}_{3}^{2-}$ groups prefer to remain independent ${ }^{53}$ but clustered with the " $\mathrm{Ti}_{2} \mathrm{O}_{7}$ " units which form as a result of oxygen vacancy, figure 3 .

$$
\mathrm{CO}_{2(\mathrm{~g})}+\mathrm{O}_{\mathrm{O}}^{\times} \rightarrow \mathrm{V}_{\mathrm{O}}^{*}+\left(\mathrm{CO}_{3}\right)_{i}^{\prime \prime}
$$

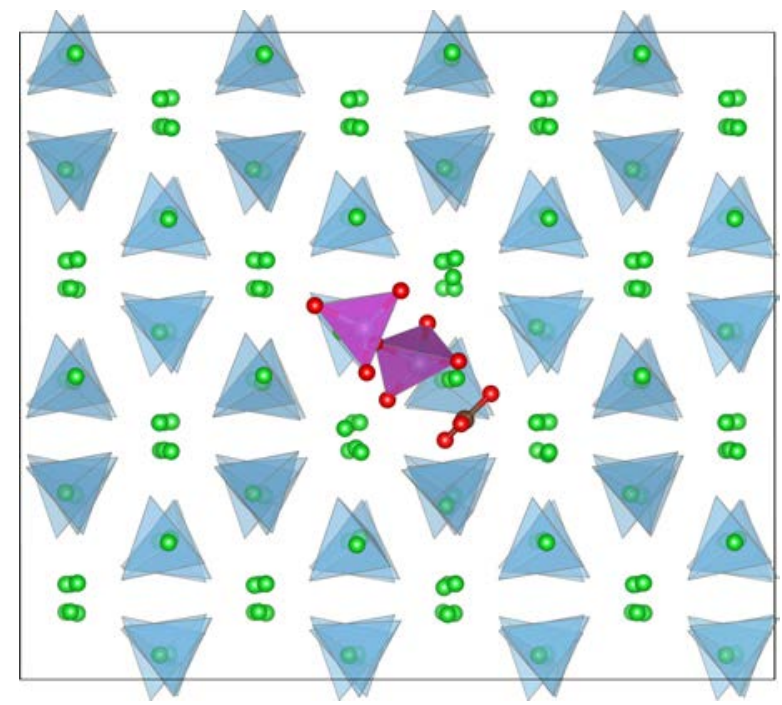

(a)

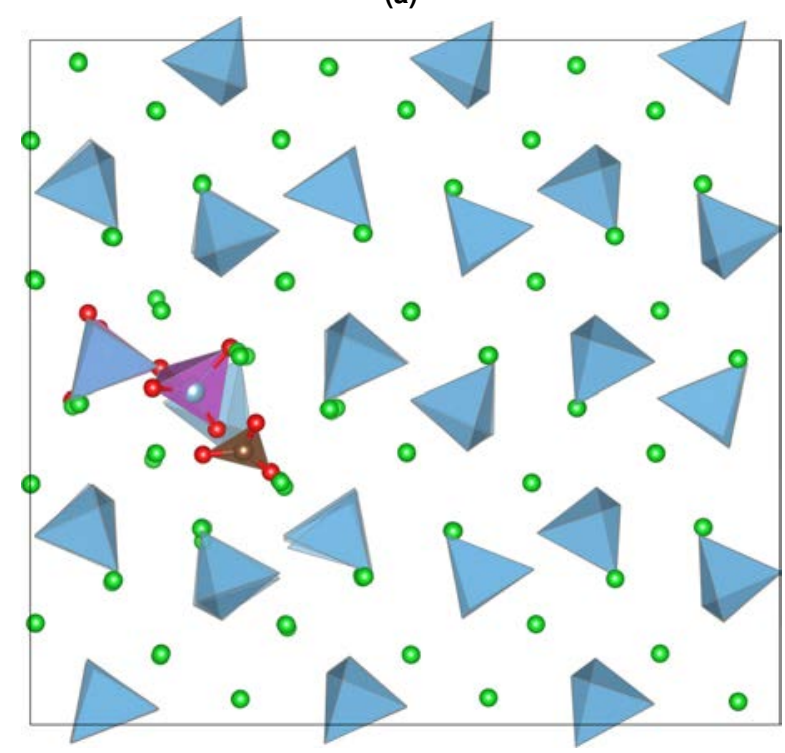

(b)

Fig. $3\left[\left(\mathrm{CO}_{3}\right)_{i}^{\prime \prime}+\mathrm{V}_{0}^{\bullet}\right]$ defect in $\alpha^{\prime}-\mathrm{Ba}_{2} \mathrm{TiO}_{4}$. Green, blue, red and brown spheres indicate $\mathrm{Ba}, \mathrm{Ti}, \mathrm{O}$ and $\mathrm{C}$ ions respectively, and blue, purple and brown polyhedra $\mathrm{TiO}_{4}, " \mathrm{Ti}_{2} \mathrm{O}_{7}$ " and $\mathrm{CO}_{3}^{2-}$ units. As viewed on the ac (a) and $b c$-planes (b). 
The second mechanism, shown in equation 10, is comparable to the previous but with its $\left(\mathrm{CO}_{3}\right)_{i}^{\prime \prime}$ and $\mathrm{V}_{\mathrm{O}}^{*}$ unclustered. The comparably high energy of this mechanism, table 4, shows a significant clustering force exists between the $\mathrm{V}_{\mathrm{O}}^{* *}$ and $\left(\mathrm{CO}_{3}\right)_{i}^{\prime \prime}$, suggesting that oxygen vacancies will be trapped and immobile. Having established the favourability of $\mathrm{CO}_{2}$ incorporation in pristine $\mathrm{Ba}_{2} \mathrm{TiO}_{4}$, attention is turned to the possible interactions with other defects e.g. oxygen interstitials or vacancies which might be induced through doping.

$$
\mathrm{CO}_{2(\mathrm{~g})}+\mathrm{O}_{i}^{\prime \prime} \rightarrow\left(\mathrm{CO}_{3}\right)_{i}^{\prime \prime}
$$

Carbonates defects could be formed through the reaction of $\mathrm{CO}_{2}$ with an oxygen interstitial, as shown in equation 11 . With an $\mathrm{E}_{\mathrm{CO}_{2}}$ value of $-2.47 \mathrm{eV}$ this mechanism is highly favourable and suggests that any oxygen interstitials present could be readily annihilated. Again, the carbonate defect is noticeably more stable in the high temperature phase. The $\left(\mathrm{CO}_{3}\right)_{i}^{\prime \prime}$ defect structure is shown in figure 4 , which shows that the carbonate group is accommodated by a displacement of the neighbouring $\mathrm{TiO}_{4}$ tetrahedra. It is interesting to note that the local arrangement of the $\mathrm{Ba}$ ions around the $\left(\mathrm{CO}_{3}\right)_{i}^{\prime \prime}$ conforms to that seen in $\mathrm{BaCO}_{3}$, which is one of the by-products of the $\mathrm{Ba}_{2} \mathrm{TiO}_{4}-\mathrm{CO}_{2}$ reaction.

$$
\mathrm{CO}_{2(\mathrm{~g})}+\mathrm{O}_{\mathrm{O}}^{\times}+\mathrm{V}_{\mathrm{O}}^{*} \rightarrow\left[\left(\mathrm{CO}_{3}\right)_{i}^{\prime \prime}+2 \mathrm{~V}_{\mathrm{O}}^{*}\right]
$$

Interactions between oxygen vacancies and carbonate defects were also considered. However, such interactions will be associative rather than a direct reaction. Mechanism 12 represents formation and further clustering of a $\left[\left(\mathrm{CO}_{3}\right)_{i}^{\prime \prime}+\mathrm{V}_{\mathrm{O}}^{*}\right]$ defect to an oxygen vacancy. This is analogous to mechanism 9 with a second oxygen vacancy clustering augment. It can be seen from the energy of this mechanism, $-3.24 \mathrm{eV}$, that the presence of oxygen vacancies will dramatically increase the favourability of carbon dioxide incorporation. Taking the difference of mechanism 9 and 12 gives a clustering energy of $-3.19 \mathrm{eV}$ suggesting oxygen vacancies formed through doping would be strongly bound to carbonate impurity defects. It can be seen from figure 5 that the presence of such a defect causes significant structural distortions in the $\mathrm{Ba}_{2} \mathrm{TiO}_{4}$ lattice and results in the formation of a " $\mathrm{Ti}_{3} \mathrm{O}_{10}$ " units in which the central Ti ion has 4 bridging oxygens.

$$
2 \mathrm{CO}_{2(\mathrm{~g})}+2 \mathrm{O}_{\mathrm{O}}^{\times} \rightarrow\left[\left(\mathrm{CO}_{3}\right)_{i}^{\prime \prime}+2 \mathrm{~V}_{\mathrm{O}}^{* *}\right]+\left(\mathrm{CO}_{3}\right)_{i}^{\prime \prime}
$$

The final mechanism, considered in equation 13 , is found to offer another low energy route towards $\mathrm{CO}_{2}$ incorporation in pristine $\mathrm{Ba}_{2} \mathrm{TiO}_{4}$. This mechanism can be thought of as the combination of mechanisms 11 and 12 with an oxygen Frenkel defect.

Finally, because carbonate defects are more stable in the $\alpha^{\prime}$ phase than the $\beta$-phase, the $\alpha^{\prime}$-phase may be stabilised by the presence of small concentrations of carbonate impurities. In this respect there have been reports that the high temperature $\alpha^{\prime}$ phase can be observed in lower temperature synthesis routes, which has been attributed to particle size effects, but may be due instead to small concentrations of carbonate impurities. ${ }^{17-20}$ Notably the modelling results showed favourable $\mathrm{CO}_{2}$ incorporation in $\alpha^{\prime}-\mathrm{Ba}_{2} \mathrm{TiO}_{4}$ in the absence of defects, while the presence of ox-

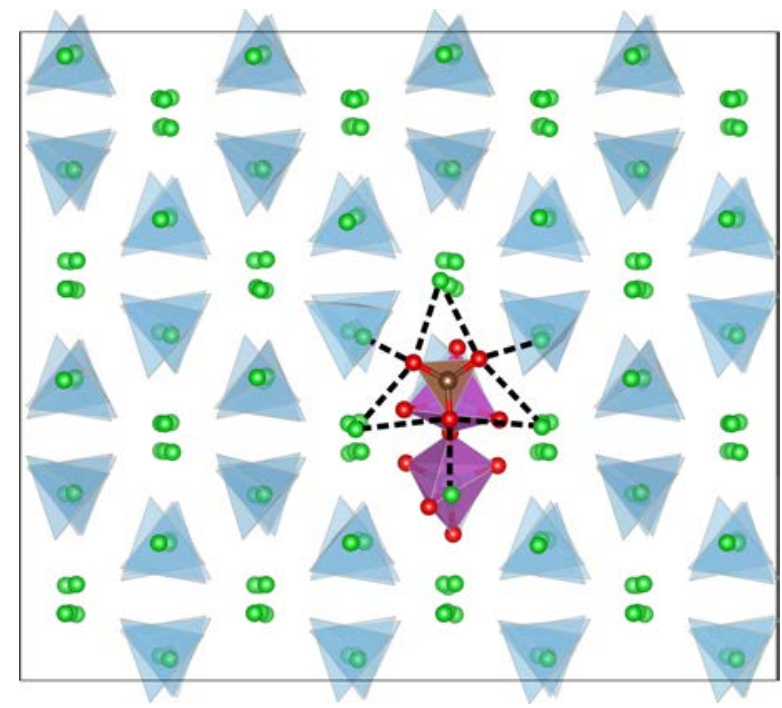

(a)

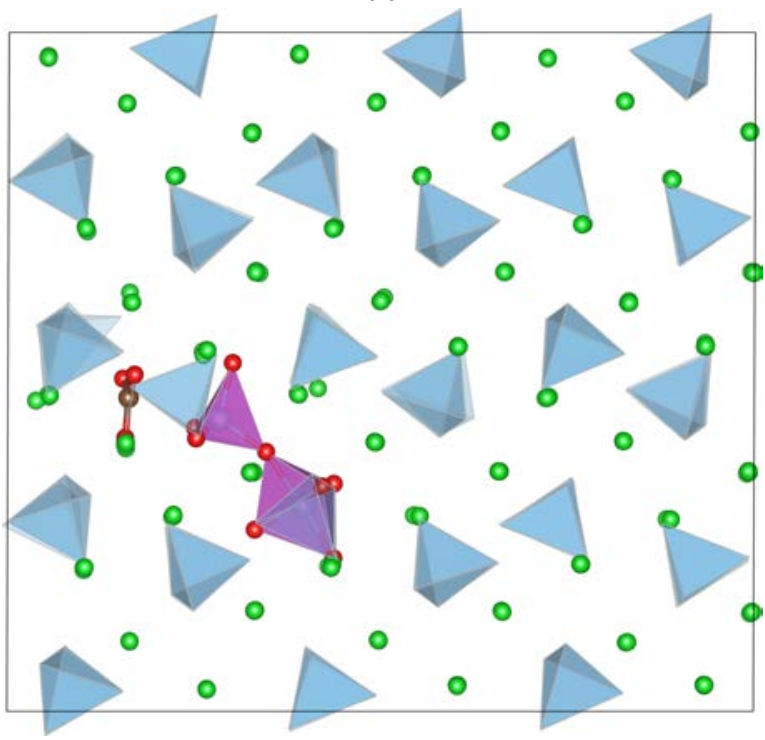

(b)

Fig. $4\left(\mathrm{CO}_{3}\right)_{i}^{\prime \prime}$ defect in $\alpha^{\prime}-\mathrm{Ba}_{2} \mathrm{TiO}_{4}$, image key identical to figure 3 but with purple polyhedra indicating a " $\mathrm{Ti}_{2} \mathrm{O}_{8}$ " unit. Dashed lines illustrate the $\mathrm{CO}_{3}^{2-}-\mathrm{Ba}$ arrangements in common with $\mathrm{BaCO}_{3}$. As viewed on the $a c$ (a) and bc-planes (b). 


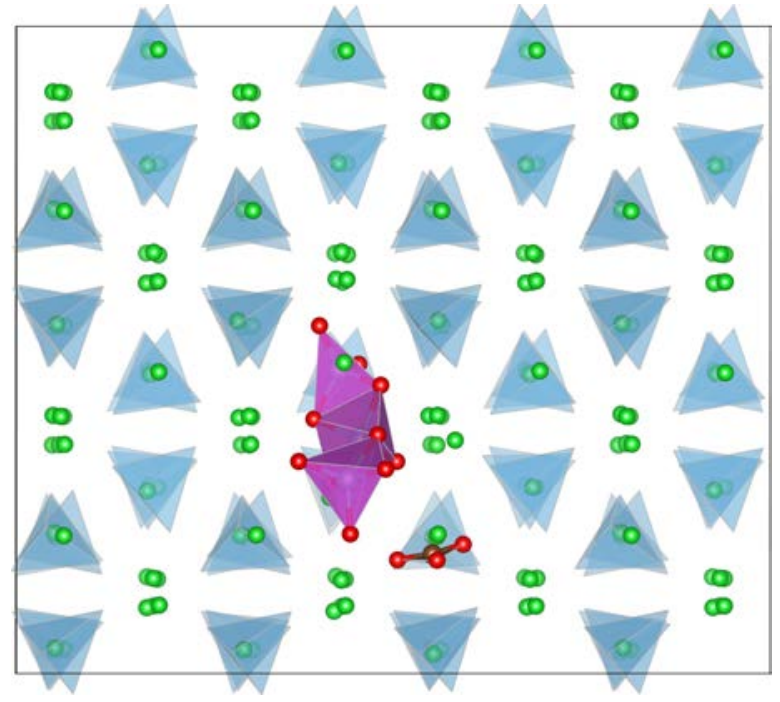

(a)

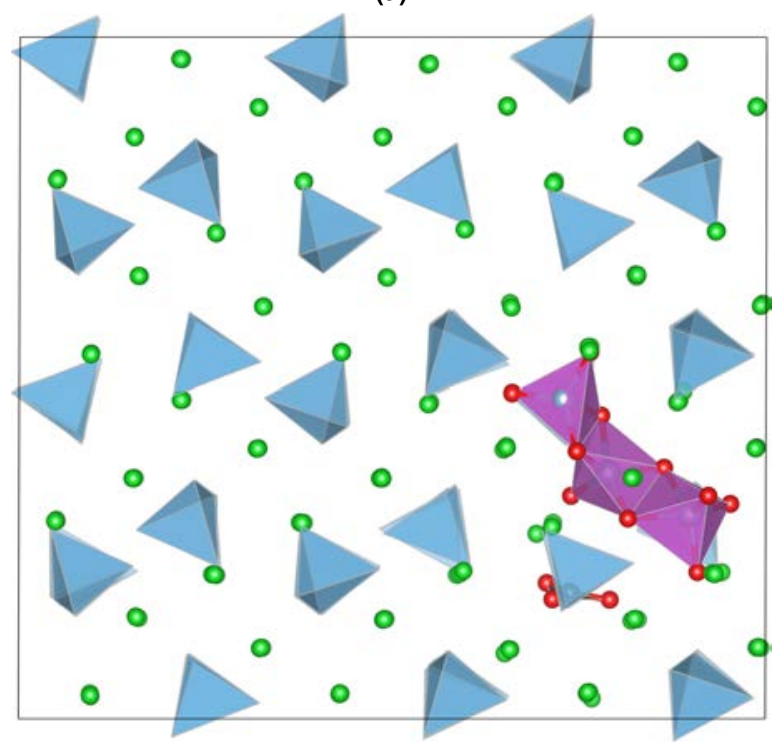

(b)

Fig. $5\left[\left(\mathrm{CO}_{3}\right)_{i}^{\prime \prime}+2 \mathrm{~V}_{0}^{\bullet \bullet}\right]$ defect in $\alpha^{\prime}-\mathrm{Ba}_{2} \mathrm{TiO}_{4}$, image key identical to figure 3 but with purple polyhedra indicating oxygen deficient " $\mathrm{Ti}_{3} \mathrm{O}_{10}$ ". As viewed on the $a c$ (a) and $b c$-planes (b).

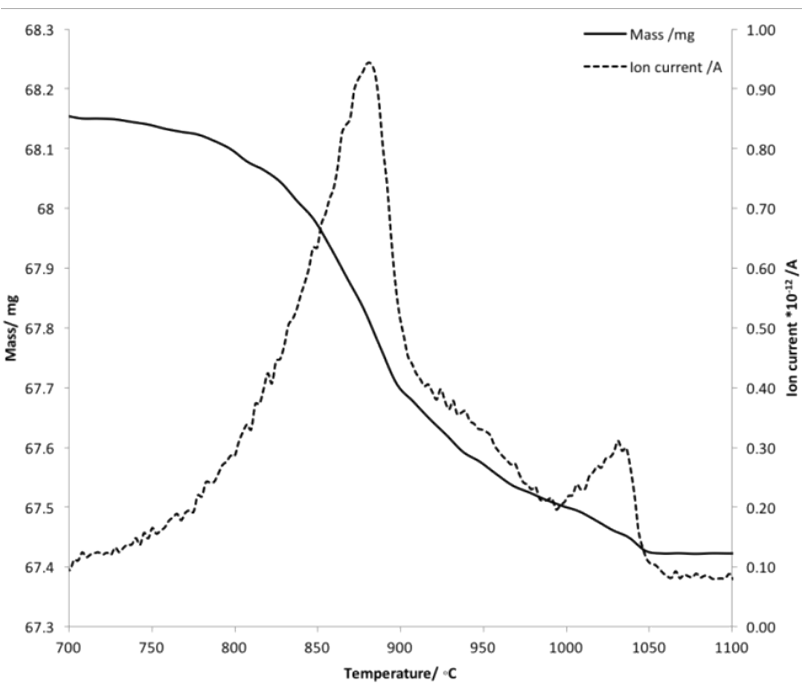

(a)

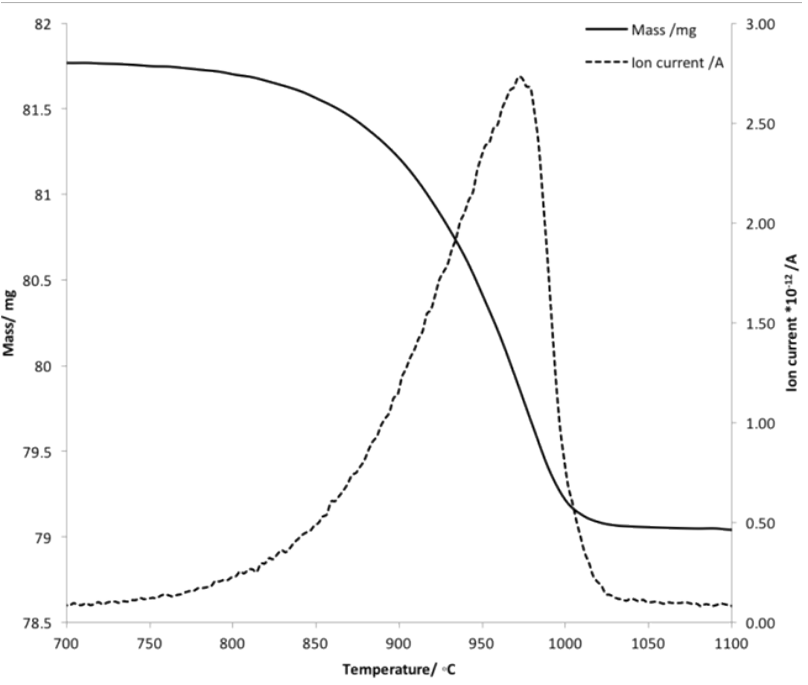

(b)

Fig. 6 (a) $\mathrm{TG}$ trace for orthorhombic $\mathrm{Ba}_{2} \mathrm{TiO}_{4}$ (prepared by annealing monoclinic $\mathrm{Ba}_{2} \mathrm{TiO}_{4}$ at $450^{\circ} \mathrm{C}$ for 8 hours in air, with an intermediate regrind). The MS trace (dashed line) shows mass losses due to $\mathrm{CO}_{2}$. The first mass loss is attributed to $\mathrm{CO}_{2}$ mass loss from orthorhombic $\mathrm{Ba}_{2} \mathrm{TiO}_{4}$ indicating a composition for this phase of $\mathrm{Ba}_{2} \mathrm{TiO}_{4} \cdot 0.09 \mathrm{CO}_{2}$ (or $\mathrm{Ba}_{2} \mathrm{TiO}_{3.91}\left(\mathrm{CO}_{3}\right)_{0.09}$ to emphasise the incorporation as carbonate). The higher temperature mass loss is attributed to the partial decomposition of some $\mathrm{Ba}_{2} \mathrm{TiO}_{4}$ to give $\mathrm{BaCO}_{3}$ and $\mathrm{BaTiO}_{3}$ which recombines to form $\mathrm{Ba}_{2} \mathrm{TiO}_{4}$ at elevated temperatures. This assignment is supported by TGA studies of a sample of $\mathrm{Ba}_{2} \mathrm{TiO}_{4}$ ( (b) ) which has been slow cooled $\left(30^{\circ} \mathrm{C} /\right.$ hour $)$ in air to room temperature, for which much higher $\mathrm{BaCO}_{3}$ levels were observed. In this case a much greater mass loss is observed, with the TGA trace dominated by the mass loss in the higher temperature region. 
ide ion vacancy or interstitial defects made the process even more favourable. Thus at the surface where defects would be more abundant due to the broken symmetry of the crystal, this $\mathrm{CO}_{2}$ incorporation process is likely to be highly favourable. Furthermore, a few examples of solution energies when taking doping into considerations have been shown in the supplementary, but since there is a fuller paper on the effects of doping in manuscript, further details on this will follow.

\subsection{Carbon Dioxide Incorporation (Experimental Studies)}

Following on from prior literature reports that $\alpha^{\prime}-\mathrm{Ba}_{2} \mathrm{TiO}_{4}$ was obtained by synthesis at lower temperatures and the modelling predictions that $\mathrm{CO}_{2}$ incorporation was favourable in this phase, even in the absence of defects, experimental studies were performed to confirm the presence of carbonate. In this work, samples of monoclinic $\beta-\mathrm{Ba}_{2} \mathrm{TiO}_{4}$ were prepared and heat treated under different conditions. The results showed that slow cooling $\left(0.5^{\circ} \mathrm{C} \mathrm{min}^{-1}\right)$ from $950{ }^{\circ} \mathrm{C}$ in $\mathrm{N}_{2}$ led to no change in X-ray diffraction pattern, while a similar heat treatment in air led to a partial change from monoclinic to orthorhombic $\mathrm{Ba}_{2} \mathrm{TiO}_{4}$. However, in addition to the presence of both $\alpha^{\prime}$ and $\beta$-phases, such a heat treatment also gave large $\mathrm{BaCO}_{3}$ and $\mathrm{BaTiO}_{3}$ impurities and so further experiments were performed heating in air for 6-8 hours at temperatures < $900{ }^{\circ} \mathrm{C}$ in order to optimise the conditions for the formation of orthorhombic $\mathrm{Ba}_{2} \mathrm{TiO}_{4}$, while limiting the partial decomposition to $\mathrm{BaCO}_{3}$ and $\mathrm{BaTiO}_{3}$. These experiments showed temperatures $<750{ }^{\circ} \mathrm{C}$ led to the appearance of the orthorhombic $\mathrm{Ba}_{2} \mathrm{TiO}_{4}$ phase, with the optimum temperature being $450{ }^{\circ} \mathrm{C}$ (figure 7). TG-MS analysis of this phase under $\mathrm{N}_{2}$ showed a small mass loss at $880{ }^{\circ} \mathrm{C}$, which MS data showed was due to $\mathrm{CO}_{2}$ loss. A composition of $\mathrm{Ba}_{2} \mathrm{TiO}_{4} \cdot 0.09 \mathrm{CO}_{2}$ (or $\mathrm{Ba}_{2} \mathrm{TiO}_{3.91}\left(\mathrm{CO}_{3}\right)_{0.09}$ to emphasise the incorporation as carbonate) was indicated, figure 6 . After the TG-MS experiment the phase obtained was monoclinic $\beta-\mathrm{Ba}_{2} \mathrm{TiO}_{4}$. Therefore these results strongly align with the modelling studies supporting the conclusion that the alpha phase is stabilised by low levels of carbonate defects, which would explain prior reports of its formation by low temperature routes17-20, since at the temperatures employed residual carbonate is likely to be present. Furthermore it indicates that the reaction of Ba2TiO4 with $\mathrm{CO} 2$ is not just limited to the surface, but rather is a mixture of bulk (migration of $\mathrm{CO} 2$, as $\mathrm{CO} 32$-, into the bulk phase) and surface processes.

\section{Conclusions}

In conclusion, this detailed computational study backed up by experimental results show:

1) that intrinsic defects will not form naturally in any significant quantity in $\mathrm{Ba}_{2} \mathrm{TiO}_{4}$

2) $\mathrm{CO}_{3}^{2-}$ defects are likely to be common impurities in both pristine and doped $\mathrm{Ba}_{2} \mathrm{TiO}_{4}$ systems; whereas those based on $\mathrm{H}_{2} \mathrm{O}$ are predicted only to form in systems which contain other supporting defects, such as oxygen vacancies or interstitials. Both carbonate and protonic defects are predicted to trap oxide ion defects.

3 ) that the $\alpha^{\prime}$-phase stabilising abilities of carbonate and protonic defects may, in part, account for the varied reports of $\mathrm{Ba}_{2} \mathrm{TiO}_{4}$ 's

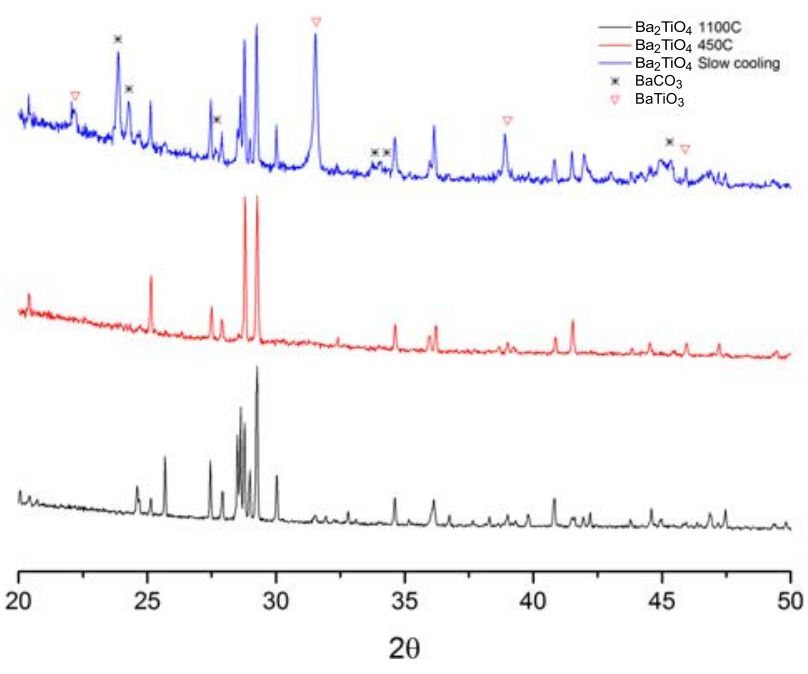

Fig. 7 XRD patterns for $\mathrm{Ba}_{2} \mathrm{TiO}_{4}$ heated under different conditions. Black: as prepared at $1100^{\circ} \mathrm{C}$ in air and furnace cooled, showing the presence of monclinic $\mathrm{Ba}_{2} \mathrm{TiO}_{4}$. Red: sample annealed at $450{ }^{\circ} \mathrm{C}$ in air for 8 hours with an intermediate regrind, showing the presence of orthorhombic " $\mathrm{Ba}_{2} \mathrm{TiO}_{4}$ ": TGA studies (figure 6) suggest a composition for this phase of $\mathrm{Ba}_{2} \mathrm{TiO}_{4} \cdot 0.09 \mathrm{CO}_{2}$ (or $\mathrm{Ba}_{2} \mathrm{TiO}_{3.91}\left(\mathrm{CO}_{3}\right)_{0.09}$ to emphasise the incorporation as carbonate). Blue: sample slow cooled in air at $30{ }^{\circ} \mathrm{C} /$ hour, showing significant decomposition to $\mathrm{BaCO}_{3}$ and $\mathrm{BaTiO}_{3}$.

phase behaviour, with our own experimental studies showing that this phase can be formed from the $\beta$-phase by heating in air at $450{ }^{\circ} \mathrm{C}$ for 6 hours, with TG studies confirming the presence of carbonate in the sample.

The work therefore highlights the importance of the consideration of the possible effect of $\mathrm{CO}_{2}$ (incorporated as $\mathrm{CO}_{3}^{2-}$ ) to rationalise the structure and properties of mixed metal oxide systems. Such consideration is also especially important, when one considers the growing use of lower temperature sol gel routes for the design and synthesis of new functional materials. Such routes are typically $\mathrm{C}$ rich, and so may introduce significant residual carbonate into the material, and so there is therefore a clear need to investigate the carbonate content of low temperature $(<1000$ ${ }^{\circ} \mathrm{C}$ ) synthesised materials, and examine how this may affect the structure and properties.

While these studies have shown some interesting results, they only relate to the materials bulk. However, it is possible that surface defect phenomena may also play an important role. Thus, further work must be conducted to investigate defect behaviour at the surface of $\mathrm{Ba}_{2} \mathrm{TiO}_{4}$.

\section{Acknowledgments}

This paper recognises the use of the 'Hydra' High Performance System at Loughborough University. Via our membership of the UK's HEC Materials Chemistry Consortium, which is funded by EPSRC (EP/L000202), this work used the ARCHER UK National Supercomputing Service (http://www.archer.ac.uk). Furthermore, PP and AJM would like to acknowledge the help of the Science-IT team at Loughborough. IT was funded through a Bolashak International Scholarship (Republic of Kazakhstan) 


\section{Supporting Information}

An appendix document accompanying this work contains additional supporting information in the form of: Interatomic potentials for $\mathrm{OH}^{-}$and $\mathrm{CO}_{3}^{2-}$; The derivation of carbonate's oxygen transfer term $\left(\mathrm{E}_{O T}\right)$; Intrinsic defect energies; An $a$-axial view of $\beta-\mathrm{Ba}_{2} \mathrm{TiO}_{4}$; Water and carbon dioxide incorporation mechanisms involving dopants to facilitate oxide ion defect formation; A table comparing interatomic distances; and another containing isolated point defect energies.

\section{References}

1 Muller-Buschbaum, H., The Crystal Chemistry of $\mathrm{AM}_{2} \mathrm{O}_{4} \mathrm{Ox}-$ ometallates, Journal of Alloys and Compounds, 2003, 349, 49104.

2 Nalbandyan, V. and Novikova, A., Structural Chemistry of $\mathrm{A}_{2} \mathrm{MX}_{4}$ Compounds $(\mathrm{X}=\mathrm{O}, \mathrm{F})$ with Isolated Tetrahedral Anions: Search for the Densest Structure Types., Acta crystallographica. Section B, Structural science, 2012, 68, 227-39.

3 Sebastian, M. T., Dielectric Materials for Wireless Communication, Elsevier Science, 2010, p. 688.

4 Lee, S.; Randall, C. A. and Liu, Z. K., Modified Phase Diagram for the Barium Oxide-Titanium Dioxide System for the Ferroelectric Barium Titanate, Journal of the American Ceramic Society, 2007, 90, 2589-2594.

5 Pfaff, G., Synthesis and Characterization of $\mathrm{Ba}_{2} \mathrm{TiO}_{4}$, Journal of Materials Science Letters, 1991, 10, 1059-1060.

6 Ritter, J. J.; Roth, R. S. and Blendell, J. E., Alkoxide Precursor Synthesis and Characterization of Phases in the BariumTitanium Oxide System, Journal of the American Ceramic Society, 1986, 69, 155-162.

7 Rase, D. E. and Roy, R., Phase Equilibria in the System BaO$\mathrm{TiO}_{2}$, Journal of the American Ceramic Society, 1955, 38, 102113.

8 Bland, J., The Crystal Structure of Barium Orthotitanate, $\mathrm{Ba}_{2} \mathrm{TiO}_{4}$, Acta Crystallographica, 1961, 14, 875-881.

9 Saito, Y.; Sato, H. and Sakabe, Y., $\mathrm{CO}_{2}$ Recovery at High Temperatures Using $\mathrm{Ba}_{2} \mathrm{TiO}_{4}$, Journal of Chemical Engineering of Japan, 2008, 41, 441-446.

10 Saito, Y. and Sakabe, Y., Development of $\mathrm{CO}_{2}$ Absorbent with Barium Orthotitanate Ceramics, Fuel Cell, 2005, 5, 5-8.

11 Reijers, H. T. J.; Elzinga, G. D.; Cobden, P. D.; Haije, W. G. and van den Brink, R. W., Tandem Bed Configuration for SorptionEnhanced Steam Reforming of Methane, International Journal of Greenhouse Gas Control, 2011, 5, 531-537.

12 Kumakiri, I.; Okamoto, T.; Murao, T.; Tanaka, K. and Kita, H., Enhanced High-temperature Carbon Sequestration with Ceramic-based Sorbents, Chemistry Letters, 2015, 44, 10161018.

13 Inoue, R.; Ueda, S.; Wakuta, K.; Sasaki, K. and Ariyama, T., Thermodynamic Consideration on the Absorption Properties of Carbon Dioxide to Basic Oxide, ISIJ International, 2010, 50, 1532-1538.

14 Parker, W. D. and Nakhmanson, S. M., Density Functional Study of the Structural, Electronic, and Vibrational Properties of $\beta$ - $\mathrm{Ba}_{2} \mathrm{TiO}_{4}$, Physical Review B, 2013, 88, 245108.

$15 \mathrm{Wu}, \mathrm{K}$. K. and Brown, I. D., The Crystal Structure of Beta Barium Orthotitanate and the Bond Strength-Bond Length Vurve of TiO, Acta Crystallographica Section B: Structural Science, 1973, 29, 2009-2012.

16 Gunter, J. R. and Jameson, G. B., Orthorhombic Barium Orthotitanate, Alpha'-Ba $\mathrm{TiO}_{4}$, Acta Crystallographica Section C: Crystal Structure Communications, 1984, 40, 207-210.

17 Lee, S. J.; Biegalski, M. D. and Kriven, W. M., Powder Synthesis of Barium Titanate and Barium Orthotitanate via an Ethylene Glycol Complex Polymerization Route, Journal of Materials Research, 1999, 14, 3001-3006.

18 Chen, B.; Liao, F.-H.; Jiao, H. and Jing, X.-P., Thermal Stability and Phase Transformation of Barium Orthotitanate $\left(\mathrm{Ba}_{2} \mathrm{TiO}_{4}\right)$, Phase Transitions, 2012, 86, 380-390.

19 Ahmad, T. and Ganguli, A. K., Synthesis of Nanometer-Sized Particles of Barium Orthotitanate Prepared Through a Modified Reverse Micellar Route: Structural Characterization, Phase Stability and Dielectric Properties, Journal of Materials Research, 2004, 19, 2905-2912.

20 Marks, O.; Günter, J. R. and Hofer, F., Electron Microscopy of Barium Ortho-Titanate and the Products of its Reaction with Carbon Dioxide, Reactivity of Solids, 1988, 6, 217-230.

21 Hancock, C. A.; Porras-Vazquez, J. M.; Keenan, P. J. and Slater, P. R., Oxyanions in Perovskites: from Superconductors to Solid Oxide Fuel Cells, Dalton Trans., 2015, 44, 1055910569.

22 Cheetham, A. K. and Day, P., Solid State Chemistry: Techniques, Clarendon Press, 1988.

23 Crabbe, J., Molecular Modelling: Principles and Applications, Prentice Hall, 1997, vol. 21, p. 185.

24 Freeman, C. M.; Gorman, A. M. and Newsam, J. M., Simulated Annealing and Structure Solution, Elsevier Science, 1997, pp. 117-150.

25 Gale, J. D., GULP: A Computer Program for the SymmetryAdapted Simulation of Solids, Journal of the Chemical Society, Faraday Transactions, 1997, 93, 629-637.

26 Gale, J. D. and Rohl, a. L., The General Utility Lattice Program (GULP), Molecular Simulation, 2003, 29, 291-341.

27 Momma, K. and Izumi, F., VESTA 3 for Three-Dimensional Visualization of Crystal, Volumetric and Morphology Data, Journal of Applied Crystallography, 2011, 44, 1272-1276.

28 Buckingham, R. A., The Classical Equation of State of Gaseous Helium, Neon and Argon, Proceedings of the Royal Society A: Mathematical, Physical and Engineering Sciences, 1938, 168, 264-283.

29 Dick, B. G. and Overhauser, A. W., Theory of the Dielectric Constants of Alkali Halide Crystals, Physical Review, 1958, 112, 90-103.

30 Tolchard, J. R.; Slater, P. R. and Islam, M. S., Insight into Doping Effects in Apatite Silicate Ionic Conductors, Advanced Functional Materials, 2007, 17, 2564-2571.

31 Bush, T. S.; Gale, J. D.; Catlow, C. R. a. and Battle, P. D., SelfConsistent Interatomic Potentials for the Simulation of Binary 
and Ternary Oxides, Journal of Materials Chemistry, 1994, 4, 831.

32 McCoy, M. A.; Grimes, R. W. and Lee, W. E., Phase Stability and Interfacial Structures in the $\mathrm{SrO}_{-} \mathrm{SrTiO}_{3}$ System, Philosophical Magazine A, 1997, 75, 833-846.

33 Morse, P., Diatomic Molecules According to the Wave Mechanics. II. Vibrational Levels, Physical Review, 1929, 34, 5764.

34 Panchmatia, P. M.; Orera, A.; Kendrick, E.; Hanna, J. V.; Smith, M. E.; Slater, P. R. and Islam, M. S., Protonic Defects and Water Incorporation in $\mathrm{Si}$ and Ge-Based Apatite Ionic Conductors, Journal of Materials Chemistry, 2010, 20, 27662772.

35 Archer, T. D.; Birse, S. E. A.; Dove, M. T.; Redfern, S. A. T.; Gale, J. D. and Cygan, R. T., An Interatomic Potential Model for Carbonates Allowing for Polarization Effects, Physics and Chemistry of Minerals, 2003, 30, 416-424.

36 Kerisit, S. and Parker, S. C., Free Energy of Adsorption of Water and Metal Ions on the $\{1014\}$ Calcite Surface, Journal of the American Chemical Society, 2004, 126, 10152-10161.

37 Mott, N. F. and Littleton, M. J., Conduction in Polar Crystals. I. Electrolytic Conduction in Solid Salts, Transactions of the Faraday Society, 1938, 34, 485.

38 Kröger, F. and Vink, H., Solid State Physics, Academic Press, 1995, vol. Volume 3, pp. 307-435.

39 Walker, A. M.; Wright, K. and Slater, B., A Computational Study of Oxygen Diffusion in Olivine, Physics and Chemistry of Minerals, 2003, 30, 536-545.

40 Islam, M. S.; Driscoll, D. J.; Fisher, C. A. J. and Slater, P. R., Atomic-Scale Investigation of Defects, Dopants, and Lithium Transport in the $\mathrm{LiFePO}_{4}$ Olivine-Type Battery Material, Chemistry of Materials, 2005, 17, 5085-5092.

41 Panchmatia, P. M.; Orera, A.; Rees, G. J.; Smith, M. E.; Hanna, J. V.; Slater, P. R. and Islam, M. S., Oxygen Defects and Novel Transport Mechanisms in Apatite Ionic Conductors: Combined $17 \mathrm{O}$ NMR and Modeling Studies, Angewandte Chemie - International Edition, 2011, 50, 9328-9333.

42 McSloy, A. J.; Kelly, P. F.; Slater, P. R. and Panchmatia, P. M., A Computational Study of Doped Olivine Structured $\mathrm{Cd}_{2} \mathrm{GeO}_{4}$ : Local Defect Trapping of Interstitial Oxide Ions, Phys. Chem. Chem. Phys., 2016, 18, 26284-26290.

43 Peroos, S.; Du, Z. and De Leeuw, N. H., A Computer Modelling Study of the Uptake, Structure and Distribution of Car- bonate Defects in Hydroxy-Apatite, Biomaterials, 2006, 27, 2150-2161.

44 Guo, P.; Wang, B.; Bauchy, M. and Sant, G., Misfit Stresses Caused by Atomic Size Mismatch: The Origin of DopingInduced Destabilization of Dicalcium Silicate, Crystal Growth and Design, 2016, 16, 3124-3132.

45 Jaffe, B.; Cook, W. R. and Jaffe, H., Piezoelectric Ceramics, Vol. 3. Non-Metallic Solids, Academic Press, London, 1971, p. 62.

46 Felgner, K. H.; Muller, T.; Langhammer, H. T. and Abicht, H. P., On the Formation of $\mathrm{BaTiO}_{3}$ from $\mathrm{BaCO}_{3}$ and $\mathrm{TiO}_{2}$ by Microwave and Conventional Heating, Materials Letters, 2004, 58, 1943-1947.

47 Kreuer, K., Proton-Conducting Oxides, Annual Review of Materials Research, 2003, 33, 333-359.

48 Orera, A. and Slater, P. R., Water Incorporation Studies in Apatite-Type Rare Earth Silicates/Germanates, Solid State Ionics, 2010, 181, 110-114.

49 Kendrick, E.; Kendrick, J.; Knight, K. S.; Islam, M. S. and Slater, P. R., Cooperative Mechanisms of Fast-Ion Conduction in Gallium-Based Oxides with Tetrahedral Moieties., Nature materials, 2007, 6, 871-875.

50 Dailly, J.; Fourcade, S.; Largeteau, A.; Mauvy, F.; Grenier, J. C. and Marrony, M., Perovskite and $\mathrm{A}_{2} \mathrm{MO}_{4}$-Type Oxides as New Cathode Materials for Protonic Solid Oxide Fuel Cells, Electrochimica Acta, 2010, 55, 5847-5853.

51 Fisher, C., Defect, Protons and Conductivity in Brownmillerite-Structured $\mathrm{Ba}_{2} \mathrm{In}_{2} \mathrm{O}_{5}$, Solid State Ionics, 1999, 118, 355-363.

52 Wright, K.; Freer, R. and Catlow, C. R. A., The Energetics and Structure of the Hydrogarnet Defect in Grossular: A Computer Simulation Study, Physics and Chemistry of Minerals, 1994, 20, 500-503.

53 Li, J.; Smith, A. E.; Jiang, P.; Stalick, J. K.; Sleight, A. W. and Subramanian, M. A., True Composition and Structure of Hexagonal "YAlO ${ }_{3}$ ", Actually $\mathrm{Y}_{3} \mathrm{Al}_{3} \mathrm{O}_{8} \mathrm{CO}_{3}$, Inorganic Chemistry, 2015, 54, 837-844.

54 de Leeuw, N. H.; Bowe, J. R. and Rabone, J. a. L., A Computational Investigation of Stoichiometric and Calcium-Deficient Oxy- and Hydroxy-Apatites., Faraday discussions, 2007, 134, 195-214; discussion 215-233, 415-419.

55 Marusawa, $\mathrm{H}$. and Saito, Y., $\mathrm{CO}_{2}$ Absorption Properties of Barium Orthotitanate under Continuous Operation, Key Engineering Materials, 2007, 350, 143-146. 


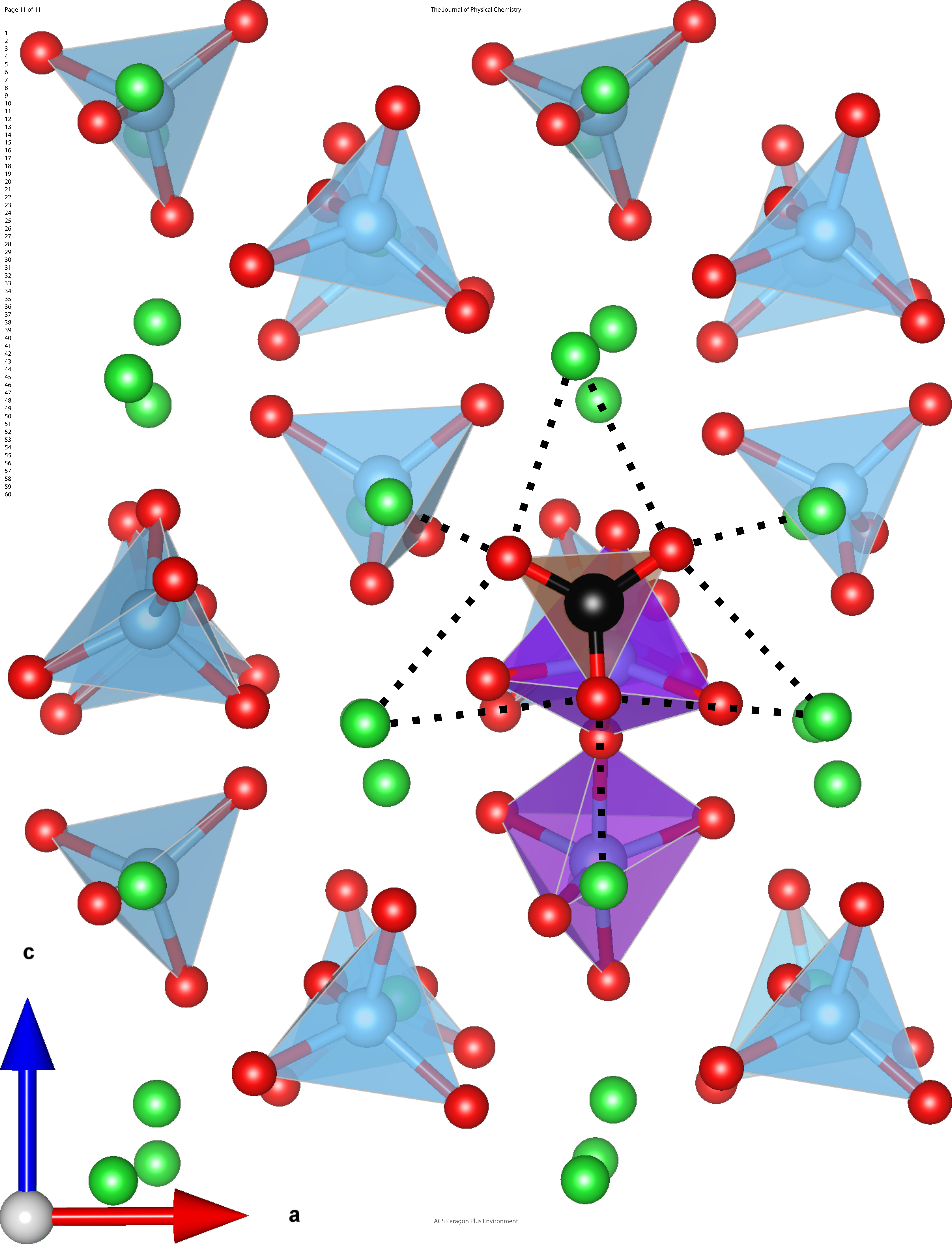

